\title{
Gastroprotective effects of irsogladine maleate on ethanol/hydrochloric acid induced gastric ulcers in mice
}

\author{
Seong Chun Kwon ${ }^{1}$ and Ji Hoon Kim ${ }^{2}$
}

\author{
${ }^{1}$ Department of Physiology, Institute \\ of Clinical and Translational \\ Research, Catholic Kwandong \\ University College of Medicine, \\ Gangneung; ${ }^{2}$ Department of \\ Surgery, Gangneung Asan Hospital, \\ University of Ulsan College of \\ Medicine, Seoul, Korea
}

Received: August 3, 2018

Revised : December 10, 2018

Accepted: February 18, 2019

\section{Correspondence to}

Ji Hoon Kim, M.D.

Department of Surgery, Gangneung Asan Hospital, University of Ulsan College of Medicine, 38 Bangdong-gil, Gangneung 25440, Korea

Tel: $+82-33-610-3220$

Fax: +82-33-641-8120

E-mail: cibax@gnah.co.kr
Background/Aims: This study was conducted to investigate the inhibitory effect of irsogladine maleate (IM) on gastric ulcers induced by ethanol and hydrochloric $\operatorname{acid}(\mathrm{HCl})$.

Methods: Mice were pretreated with IM for 1 hours before ulcer induction. Gastric ulcers were induced by oral administration of an ethanol/HCl mixture. To clarify the action mechanism of IM, the roles of 3'5'-cyclic adenosine monophosphate (cAMP), nitric oxide (NO), adenosine triphosphate-sensitive potassium $\left(\mathrm{K}_{\mathrm{ATP}}\right)$ channels, prostaglandins and transient receptor potential cation channel subfamily V member 1 (TRPVI) were investigated, and lipid peroxidation in the stomach of IM-treated and -untreated animals was also measured.

Results: IM significantly reduced the extent of ethanol/HCl mixture-induced gastric ulceration. It exhibited dose-related gastroprotection against the ethanol/ HCl-induced lesions, while pretreatment with glibenclamide but not $\mathrm{N}(\omega)$-nitro-L-arginine methyl ester, reversed this action. While pretreatment with the TRPV1 antagonist capsazepine failed to effectively block the gastroprotective effect of IM, the non-selective cyclooxygenase inhibitor indomethacin almost abolished it. IM also decreased the level of thiobarbituric acid reactive substances.

Conclusions: We concluded that IM exhibited significant gastroprotective effects in an ethanol/HCl-induced ulcer model, which appear to be mediated, at least in part, by NO, cAMP, endogenous prostaglandins, $\mathrm{K}_{\mathrm{ATP}}$ channel opening, activation of TRPVı channels, and antioxidant properties.

Keywords: Irsoglandine maleate; Anti-ulcer; Stomach ulcer

\section{INTRODUCTION}

Gastric ulcer is one of the most common digestive diseases worldwide. Multiple pathogenic factors can cause the disease including, chronic inflammation due to exogenous factors, stress, smoking, nonsteroidal anti-inflammatory drugs (NSAIDs), Helicobacter pylori, and alcohol ingestion. Alcohol is one of the most common pathogenic factors of gastric injury [1]. Excessive alco- hol consumption can weaken the protective function of the gastric mucosa. Alcohol is well-known to induce damage to the gastric mucosa including edema, erosion, ulcerative lesions, hemorrhage and infiltration of inflammatory cells in animal studies [2]. Ethanol and hydrochloric acid ( $\mathrm{HCl})$ could cause an imbalance between some endogenous aggressive and protective factors. Pathogenesis of gastric ulcer involves the generation of oxygen-derived free radicals such as superoxide anion 
radical and hydroxyl radicals, lipid peroxides, and the infiltration of neutrophils [3]. Infiltration of neutrophils into the gastric mucosal tissue can be evaluated by measuring myeloperoxidase (MPO) activity. Gastric mucosal cells secrete antioxidant substances, such as superoxide dismutase (SOD) and glutathione (GSH), to inhibit reactive oxygen species (ROS). When the gastric mucosa is injured, ROS are secreted continuously and cause lipid peroxidation, which suppresses antioxidant activity. It has been known that lipid peroxidation is involved in the pathogenesis of gastric mucosal lesions [4]. Antioxidant agents, such as vitamin E, catechin and astaxanathin are also known to inhibit the product of lipid peroxidation and subsequently, ethanol-induced gastric ulcers in animal models $[5,6]$. The antioxidant activity of 2,4-diamino-6(2,5-dichlorophenyl)-s-triazine maleate (irsogladine maleate [IM]) has been reported to be approximately 100 times greater than that of vitamin E [7]. Additionally, IM treatment has been shown to ameliorate lesions of the small intestine in rats induced by indomethacin, and protects against neutrophil migration and E-cadherin expression [8]. Therefore, it is necessary to investigate the balance between ROS and antioxidant activity in the study of ethanol-induced gastric mucosal damage.

IM is a drug widely used in Japan for the treatment of gastric ulcers [7,9], which was first released as MN1695, but currently called IM. The therapeutic effect of $\mathrm{IM}$ is associated with a marked increase in gastric mucosal blood flow and an improvement in the function of the gastric mucosal barrier, with no side effects on systemic blood pressure and respiration [9]. In gastric injury induced by monochloramine, IM significantly increased the gastric blood flow and enhanced the immune response, which greatly reduced gastric lesions [10]. These effects were mediated by increased the intracellular level of $3{ }^{\prime} 5^{\prime}$-cyclic adenosine monophosphate (cAMP) through inhibition of phosphodiesterase (PDE) [11]. It is known that some of the protective effects of IM, which are mediated by an increase in intracellular cAMP level, are caused by an in increase in endogenous nitric oxide (NO) concentration [12].

Many experimental models have been created and used to study gastric mucosal injuries. Among them, experimental models using ethanol/ $\mathrm{HCl}$ to induce gastric ulcers have been widely used to study the pathogen- esis and progression of gastric lesions and to evaluate therapeutic approaches [7]. The anti-inflammatory and protective effects of IM on the gastric ulcer induced by NSAIDs are well known, but little is known about the action mechanisms of IM on ethanol/HCl-induced gastric ulcers $[13,14]$. Thus, the goal of the present study was to examine the protective mechanisms of IM on ethanol/ $\mathrm{HCl}$-induced gastric lesions in mice and to provide its antiulcer mechanism of action.

\section{METHODS}

\section{Animals}

Male ICR mice, weighing 25 to $30 \mathrm{~g}$ (supplied by SamtakoBio, Osan, Korea) were used in all experiments. The animals were adapted for 7 days under, a controlled temperature of $22^{\circ} \mathrm{C} \pm 2{ }^{\circ} \mathrm{C}$ under a 12 hours light/dark cycle (lights on from 8:00 AM to 8:00 PM) and free access to food and water. All experimental procedures were performed in agreement with the regulations stipulated by the guide for the care and use of laboratory animals prepared by our institute.

\section{Ethanol and $\mathrm{HCl}$-induced gastric ulcer}

Acute gastric lesions were induced by oral administration of $0.1 \mathrm{~mL} / 20 \mathrm{~g}$ of a mixture containing $0.15 \mathrm{M} \mathrm{HCl}$ in $98 \%$ ethanol, a dose that induces significant gastric ulceration. After 24 hours food deprivation, groups of animals ( $\mathrm{n}=5$ /group) were orally administered different doses of IM $(1 \mathrm{mg} / \mathrm{kg}$ and $10 \mathrm{mg} / \mathrm{kg}$ or the vehicle $1.5 \%$ carboxymethylcellulose solution dissolved in distilled water). Then, 1 hour after oral treatment with the above solutions, the animals were administered orally $0.2 \mathrm{~mL}$ ethanol or the ethanol/HCl mixture and 1 hour later, they were euthanized, the stomachs were removed, and then incised along the greater curvature. The stomachs were gently rinsed with saline solution to remove the gastric contents and blood clots, and then images were captured using a digital camera. The total and injured stomach sizes were measured using a software (Angiogenesis Image Analyzer, KURABO, Osaka, Japan) and expressed as percentages of the mucosal lesions.

\section{Histological analysis}

After macroscopic analysis, a small portion of each 
stomach was fixed in $4 \%$ formalin solution for 24 hours. Stomach tissue sections were dehydrated with graded concentrations of ethanol, passed through xylene, and embedded in paraffin. The paraffin sections $(5 \mathrm{~mm}$ thick) were stained with hematoxylin and eosin (H\&E).

\section{Assessment of cAMP}

To assay cAMP levels, the glandular segment of each stomach was homogenized in an ice-cold 0.02\% EDTA solution (100\%) and assayed for cAMP using a cAMP enzyme immunoassay system (Amersham Biosciences) according to the instructions provided by the manufacturer.

\section{Evaluation of role of NO, $\mathrm{K}_{\text {ATP }}$ channel, prostaglan- din, and TRPV 1}

To study the possible mechanism of action of IM, separate experiments were conducted using the following drugs: N( $\omega)$-nitro-L-arginine methyl ester (L-NAME), an inhibitor of the NO synthase activity $(20 \mathrm{mg} / \mathrm{kg}$, intraperitoneal); glibenclamide, a blocker of adenosine triphosphate-sensitive potassium $\left(\mathrm{K}_{\mathrm{ATP}}\right)$ channels $(10 \mathrm{mg} /$ $\mathrm{kg}$, intraperitoneal); diazoxide, a $\mathrm{K}_{\mathrm{ATP}}$ channel opener (3 $\mathrm{mg} / \mathrm{kg}$, intraperitoneal); indomethacin (10 mg/kg, orally); capsaicin, a transient receptor potential cation channel subfamily V member 1 (TRPV1) activator $(0.3 \mathrm{mg} / \mathrm{kg}$, intraperitoneal); capsazepine, a TRPV1 antagonist (5 mg/ $\mathrm{kg}$, intraperitoneal), and misoprostol (100 $\mu \mathrm{g} / \mathrm{kg}$, orally). L-NAME and glibenclamide were administered $30 \mathrm{~min}$ utes before IM (10 mL/kg, orally) with L-arginine (6oo $\mathrm{mg} / \mathrm{kg}$, orally). Indomethacin was administrated 2 hours before IM (10 mL/kg, orally) or capsaicin, and 1 hour after the induction of ulcers with $0.2 \mathrm{~mL}$ ethanol/HCl, all animals were euthanized, and their stomachs were removed for examination.

\section{Determination of thiobarbituric acid reactive sub- stance levels}

The in vitro model of lipid peroxidation was prepared using a supernatant fraction of a stomach homogenate prepared from male ICR mice. Stomach tissues were homogenized using a Hiscotron homogenizer in 5 volumes of ice-cold $1.15 \%$ sodium chloride. The stomach homogenate was centrifuged at 3,000 rpm for 10 minutes. A 945 $\mathrm{mL}$ volume of the stomach homogenate supernatant was added to $5 \mathrm{~mL}$ of the test compound followed by 50
$\mathrm{mL} \mathrm{FeSO}$, and then the mixture was incubated at $37^{\circ} \mathrm{C}$ for 1 hour. The reaction was stopped by adding $200 \mathrm{~mL}$ of $35 \%$ perchloric acid $\left(\mathrm{HClO}_{4}\right)$, and then centrifuged at 3,000 rpm for 10 minutes. A $500 \mathrm{~mL}$ aliquot of the supernatant was heated with $500 \mathrm{~mL}$ of thiobarbituric acid reactive substances (TBARS), $750 \mathrm{~mL}$ phosphate buffer, and $100 \mathrm{~mL}$ sodium dodecyl sulfate (SDS) for 60 minutes at $100^{\circ} \mathrm{C}$. After cooling, an equivalent amount of n-butanol was added, the tube was shaken vigorously for 1 minute, and then centrifuged for 10 minutes at 4,000 rpm. The absorbance was measured spectrophotometrically at 532 $\mathrm{nm}$. The tissue levels of TBARS were calculated from a standard curve plotted using different concentrations of 1,1,3,3-tetraethoxy propane and expressed as nanomolar per gram of tissue (nM/g tissue) [15].

\section{Data analysis}

All the data are shown as means $\pm \mathrm{SD}$. A one-way analysis of variance followed by Dunn's (post hoc) test were performed to compare the drug-treated groups. The number of preparations sampled from separate animals was indicated by number and $p<0.05$ were considered statistically significant.

\section{RESULTS}

\section{Macroscopic and histological effects of IM on ethanol and ethanol/ $\mathrm{HCl}$-induced gastric mucosal lesions}

Macroscopic analysis of the gastric mucosa showed that acute gastric mucosal lesions were induced by orally administration of pure ethanol or ethanol/ $\mathrm{HCl}$ (Fig. 1A1D). The gastric mucosal injury area was approximately 3.5 times larger following treatment with ethanol/HCl than with ethanol alone (Table 1). Pretreatment with IM (1 and $10 \mathrm{mg} / \mathrm{kg}$ ) produced a significant dose-dependent reduction in the ethanol/HCl-induced gastric mucosal lesions compared with the vehicle-treatment (Table 1, Fig. $1 \mathrm{C}$ and $1 \mathrm{D}$ ). IM at the tested doses of 1 and $10 \mathrm{mg} /$ kg exhibited a significant, dose-dependent protective effect against ethanol/HCl-induced gastric lesions, Furthermore, compared to the vehicle group, the extent of inhibition by 1 and $10 \mathrm{mg} / \mathrm{kg} \mathrm{IM}$ was $15 \%$ and $84 \%$, respectively.

Histological analysis showed that ethanol only slight- 
ly damaged the gastric mucosa (Fig. $1 \mathrm{E}$ ), whereas ethanol/HCl extensively disrupted the superficial region of the gastric gland with epithelial cell loss, edema, and intense hemorrhage in the glandular portion of the stomach (Fig. 1 F). Furthermore, $1 \mathrm{mg} / \mathrm{kg}$ IM pretreatment slightly reduced the gastric mucosal damage by ethanol/HCl, while $10 \mathrm{~mL} / \mathrm{kg}$ IM pretreatment restored

Table 1. Effect of IM on the level of gastric mucosal injury area in ethanol/HCl-challenged mice

\begin{tabular}{lcc}
\hline Group & $\begin{array}{c}\text { Gastric mucosal } \\
\text { injury area, } \mathrm{mm}^{2}\end{array}$ & Inhibition, \% \\
\hline Ethanol & $2.62 \pm 0.95$ & \\
Ethanol/HCl & $9.28 \pm 3.27$ & $15.0 \pm 4.3$ \\
$1 \mathrm{mg} / \mathrm{kg} \mathrm{IM}$ & $7.86 \pm 2.4^{\mathrm{a}}$ & $84.2 \pm 3.84$ \\
\hline $10 \mathrm{mg} / \mathrm{kg} \mathrm{IM}$ & $1.42 \pm 0.4^{\mathrm{b}}$ & \\
\hline
\end{tabular}

Values are presented as mean $\pm \operatorname{SD}(n=5)$.

IM, irsogladine maleate; $\mathrm{HCl}$, hydrochloric acid.

${ }^{\mathrm{a}} \mathrm{p}<0.05$.

${ }_{p} p<0.05$ compared with control.
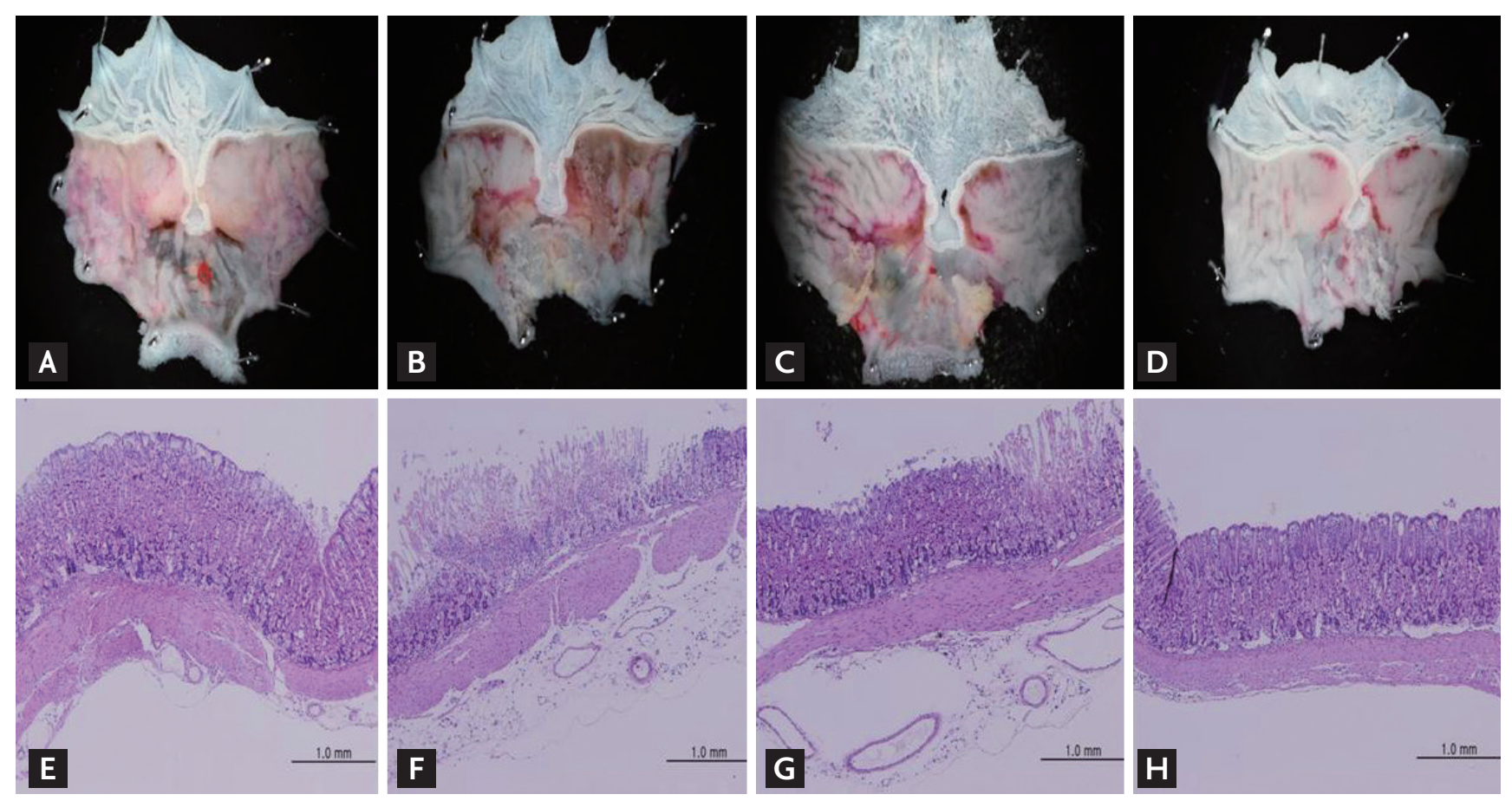

the gastric mucosa closer to normal levels (Fig. $1 \mathrm{G}$ and ${ }_{1 H} \mathrm{H}$. Since the inhibitory effect of IM on the gastric ulceration was significant at $10 \mathrm{mg} / \mathrm{kg}$, we investigated the gastroprotective mechanism using this model and choosing a $10 \mathrm{mg} / \mathrm{kg}$ dose of IM.

\section{Synergic effects of IM and SNAP on cAMP content}

Previous studies showed that the effects of IM and NO are mediated by cAMP signaling and IM and NO may additively activate the cAMP signal pathway [11,12]. To confirm this, the intracellular cAMP contents were measured. Table 2 shows that IM (10 mg/kg) or S-nitroso acetyl penicillamine (SNAP, $100 \mu \mathrm{M}$ ) alone slightly, but significantly increased cAMP and in combination, they synergistically elevated the cAMP contents.

\section{Effects of L-arginine and L-NAME on IM-induced gastroprotection}

Fig. 2 shows the effects of L-NAME pretreatment on the gastroprotective effect of IM (10 mg/kg). Ethanol/ $\mathrm{HCl}$-induced gastric mucosal lesion was $35.5 \% \pm 6.5 \%$ (n

Figure 1. Effect of irsogladine maleate (IM) on the macroscopic changes of gastric mucosal lesions induced by (A) ethanol and (B-D) ethanol/hydrochloric acid ( $\mathrm{HCl})$ in mice. Stomach tissue treated without (B) and pretreated with IM at the doses of $(\mathrm{C}) 1$ $\mathrm{mg} / \mathrm{kg}$ or (D) $10 \mathrm{mg} / \mathrm{kg}$, respectively, 1 hour before administration of ethanol/HCl. Six mice were used in each group. Histologic appearance of gastric mucosal lesions induced by (E) ethanol and (F-H) ethanol/HCl in mice. Photomicrographs of H\&E staining of gastric mucosa (magnification $\times 100)$ : (E) ethanol, (F) ethanol $/ \mathrm{HCl},(\mathrm{G})$ ethanol $/ \mathrm{HCl}+1 \mathrm{mg} / \mathrm{kg} \mathrm{IM},(\mathrm{H})$ ethanol $/ \mathrm{HCl}+$ $10 \mathrm{mg} / \mathrm{kg}$ IM. 
=5) of the total gastric size. Both IM (10 mg/kg) and L-arginine alone significantly decreased the mucosal lesions to $8.4 \% \pm 2.1 \%$ and $10.4 \pm 3 \%$ (both, $\mathrm{n}=5$ ), respective-

Table 2. Effect of IM on the level of cAMP in ethanol/ HCl-challenged mice

\begin{tabular}{lcc}
\hline Group & cAMP, pmol/mg protein & Increase, \% \\
\hline Vehicle & $3.4 \pm 0.6$ & 100 \\
10 mg/kg IM & $5.8 \pm 1.2^{\mathrm{a}}$ & $165 \pm 24$ \\
SNAP & $4.8 \pm 0.9$ & $148 \pm 16$ \\
SNAP + 10 mg/ & $8.3 \pm 1.5^{\mathrm{b}}$ & $243 \pm 20$ \\
kg IM & & \\
\hline
\end{tabular}

Values are presented as mean $\pm \operatorname{SD}(n=5)$.

IM, irsogladine maleate; cAMP, $3^{\prime} 5^{\prime}$-cyclic adenosine monophosphate; $\mathrm{HCl}$, hydrochloric acid; SNAP, S-nitroso acetyl penicillamine.

${ }^{a} p<0.05$.

${ }_{\mathrm{b}} \mathrm{p}<0.01$ compared with control.

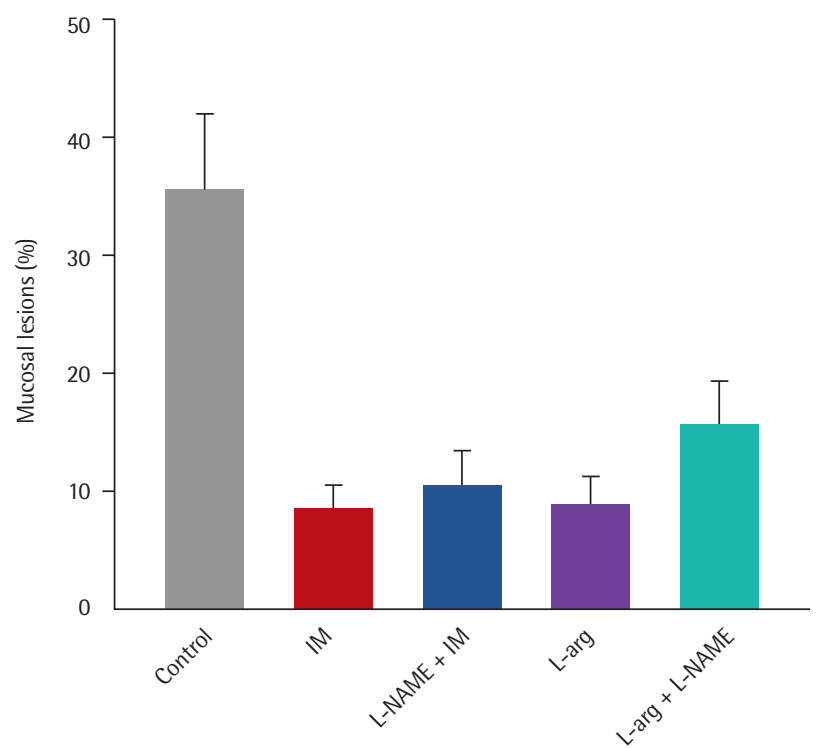

Figure 2. Involvement of nitric oxide (NO) in the gastroprotection of irsogladine maleate (IM) in mice subjected to ethanol/hydrochloric acid ( $\mathrm{HCl}$-induced gastric damage. $\mathrm{N}(\omega)$-Nitro-L-arginine methyl ester (L-NAME) $(20 \mathrm{mg} / \mathrm{kg}$, intraperitoneal), or vehicle were injected 30 minutes before the administration of IM (10 mg/kg, orally) or water to each group. Sixty minutes after, gastric mucosal lesions were induced with ethanol/HCl (20 mL, orally) in all groups. Each value represents the mean $\pm \mathrm{SD}$ of the percentage of ulcerated gastric area $(n=5 /$ group$)$. ly. L-NAME $(20 \mathrm{mg} / \mathrm{kg}$ ) slightly and, not significantly, blocked the gastroprotection produced by IM and L-arginine $(600 \mathrm{mg} / \mathrm{kg})$, suggesting the likely involvement of NO.

\section{Effects of glibenclamide and diazoxide on IM-in- duced gastroprotection}

Fig. 3 presents the results of the effects of glibenclamide and diazoxide on the gastroprotection by IM. IM (10 mg/ $\mathrm{kg}$ ) or diazoxide $(3 \mathrm{mg} / \mathrm{kg}$ ) alone reduced the ethanol/ $\mathrm{HCl}$-induced gastric mucosal lesions to $8.4 \% \pm 2.1 \%$ and $16.7 \% \pm 4.5 \%$ (both, $n=5$ ), respectively. Pretreatment with the $\mathrm{K}_{\text {ATP }}$ channel blocker, glibenclamide (10 mg/kg), also slightly, and not significantly reduced the gastroprotective effect of IM and diazoxide, indicating a role for $\mathrm{K}_{\text {ATP }}$ channels in the gastroprotection.

As shown in Fig. 4, IM (10 mg/kg) or capsaicin (0.3 mg/ $\mathrm{kg}$ ) alone reduced the ethanol/HCl-induced gastric mu-

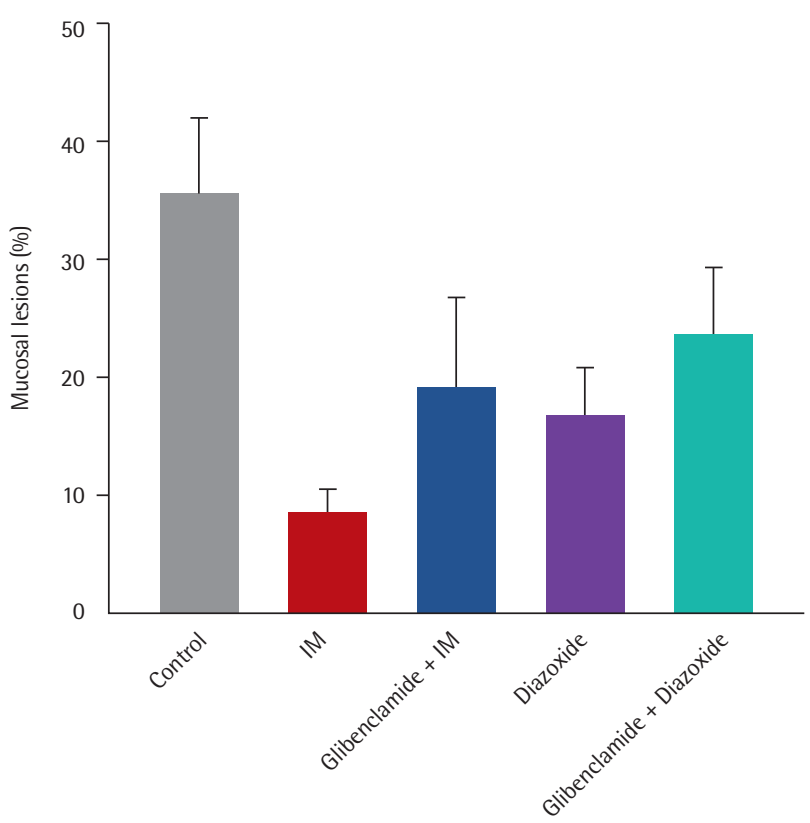

Figure 3. Effects of the pretreatment with glibenclamide on gastroprotection of irsogladine maleate (IM) in mice subjected to ethanol/hydrochloric acid ( $\mathrm{HCl})$-induced gastric damage. Glibenclamide (10 mg/kg, intraperitoneal) or vehicle was injected 30 minutes before the administration of IM ( $1 \mathrm{mg} / \mathrm{kg}$, orally) or water to each group. Sixty minutes after, gastric mucosal lesions were induced with ethanol/HCl (2O $\mathrm{mL}$, orally) in all groups. Each value represents the mean \pm $\mathrm{SD}$ of the percentage of ulcerated gastric area ( $\mathrm{n}=5$ /group). 
cosal lesions to $9.5 \% \pm 2.7 \%$ and $11.4 \% \pm 3.3 \%$ (both, $\mathrm{n}=$ 5), respectively. Pretreatment with the TRPV antagonist capsazapine $(5 \mathrm{mg} / \mathrm{kg}$ ) reduced the inhibitory effect of IM or capsaicin slightly, but statistically significantly.

\section{Effects of capsazapine and indomethacin pretreat- ments on IM-induced gastroprotection}

As shown in Fig. 4, IM (10 mg/kg) or capsaicin (0.3 mg/ $\mathrm{kg}$ ) alone reduced the ethanol/HCl-induced gastric mucosal lesions to $9.5 \% \pm 2.7 \%$ and $11.4 \% \pm 3.3 \%(n=5)$, respectively. Pre-treatment with the TRPV antagonist capsazapine $(5 \mathrm{mg} / \mathrm{kg})$, reduced the inhibitory effect of IM or capsaicin slightly, but significantly.

As shown in Fig. 5 , both IM (10 mg/kg) and misoprostol $(100 \mu \mathrm{g} / \mathrm{kg})$ alone significantly decreased the mucosal lesion to $9.5 \% \pm 2.7 \%$ and $11.4 \% \pm 3.3 \%(n=5)$, respectively. When indomethacin $(10 \mathrm{mg} / \mathrm{kg})$ was pretreated with IM or misoprostol and capsaicin, the inhibitory effect of IM or misoprostol was slightly reduced, but the effect was statistically significant.

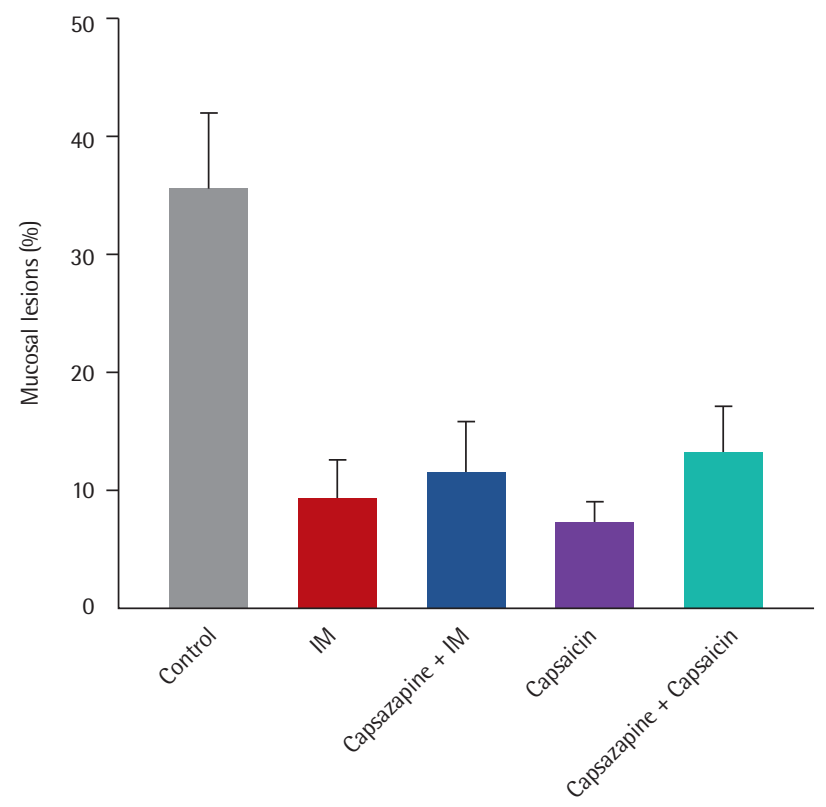

Figure 4. Role of vanilloid receptors (transient receptor potential cation channel subfamily V member 1 [TRPV1]) in gastroprotection of irsogladine maleate (IM) in mice subjected to ethanol/hydrochloric acid ( $\mathrm{HCl})$-induced gastric damage. Capsazepine $(5 \mathrm{mg} / \mathrm{kg}$, intraperitoneal) or vehicle were injected 30 minutes before the administration of IM (1 $\mathrm{mg} / \mathrm{kg}$, orally) or water to each group. Sixty minutes after, gastric mucosal lesions were induced with ethanol/HCl (2O $\mathrm{mL}$, orally) in all groups. Each value represents the mean \pm $\mathrm{SD}$ of the percentage of ulcerated gastric area ( $n=5 /$ group).

\section{Effect of IM on TBARS levels in ethanol/ $\mathrm{HCl}$ - in- duced gastric mucosal lesions}

The TBARS levels of the murine stomach homogenates were measured to provide an index of lipid peroxidation, which is known to be associated with gastric ulcers. The TBARS level increased after 1 hour incubation with $\mathrm{FeSO}_{4}$ at $37^{\circ} \mathrm{C}$ in the vehicle-treated group. As shown in Fig. $6,1 \mathrm{mg} / \mathrm{kg}$ and $10 \mathrm{mg} / \mathrm{kg}$ IM significantly inhibited the production of TBARS (from $57.2 \pm 8.4$ to $40.5 \pm 7.4$ and $28.9 \pm 5.4 \mathrm{nM} / \mathrm{g}$ tissue, $\mathrm{n}=5$ ). The antioxidant trolox (a water-soluble vitamin E derivative) administered at 25 $\mathrm{mg} / \mathrm{mL}$ also inhibited the production of TBARS (from $57.2 \pm 8.4$ to $39.22 \pm 6.2 \mathrm{nM} / \mathrm{g}$ tissue, $\mathrm{n}=5$ ).

\section{DISCUSSION}

In the present study, we investigated the anti-gastric ulcer properties of IM using ethanol/HCl to induce

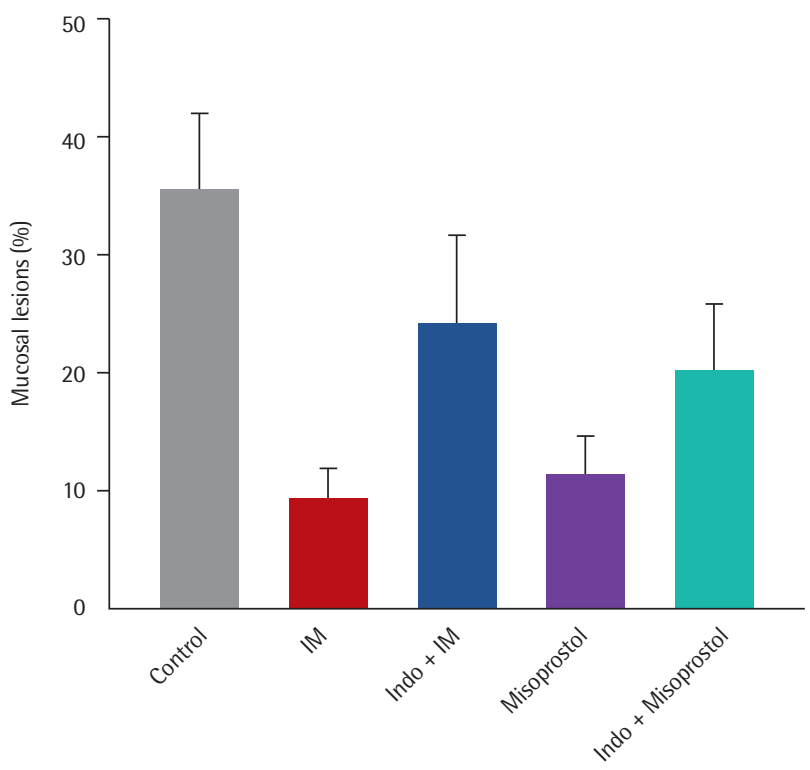

Figure 5. Effect of pretreatment with indomethacin on the gastroprotection of irsogladine maleate (IM) in mice subjected to ethanol/ ydrochloric acid ( $\mathrm{HCl}$ )-induced gastric ulceration. Mice were pretreated with IM (10 mg/kg), indomethacin (10 mg/kg), misoprostol (100 mg/kg, orally) or combination of indomethacin and misoprostol or IM. Sixty minutes after, gastric mucosal lesions were induced with ethanol/HCl (20 mL, orally) in all groups. Each value represents the mean $\pm \mathrm{SD}$ of the percentage of ulcerated gastric area ( $n=6 /$ group). 
establish an experimental model of gastric ulcers. The major findings of this study are as follows: (1) orally administration of ethanol/HCl induced a more significant gastric ulceration than ethanol did alone; (2) IM significantly reduced the size of gastric mucosal lesions in a dose-dependent manner; (3) IM increased the intracellular NO and cAMP levels; (4) IM increased the endogenous prostaglandins and activation of TRPVı channels; (5) IM reduced TBARS activity to produce antioxidant activity.

In this study, different doses of IM were tested on ethanol/HCl-induced gastric ulcers to determine the possible effective doses required to induce anti-ulcer effects. The results showed that pretreatment with IM reduced the gastric damage induced by ethanol/ $\mathrm{HCl}$ at the higher dose. The results of the macroscopic and histological analysis showed that ethanol/HCl administration caused gastric mucosa injuries characterized by hemorrhage, mucosal edema, epithelial cell loss, and inflammatory cell infiltration, in accordance with several previously described studies [16-19]. The size of gastric ulcer caused by ethanol/HCl was greatly reduced by pretreatment with IM, which also inhibited the alterations. These results indicate the significant gastroprotective effect of IM against ethanol/HCl-induced mucosal damage, and IM probably act as a gastric mucosal protective agent.

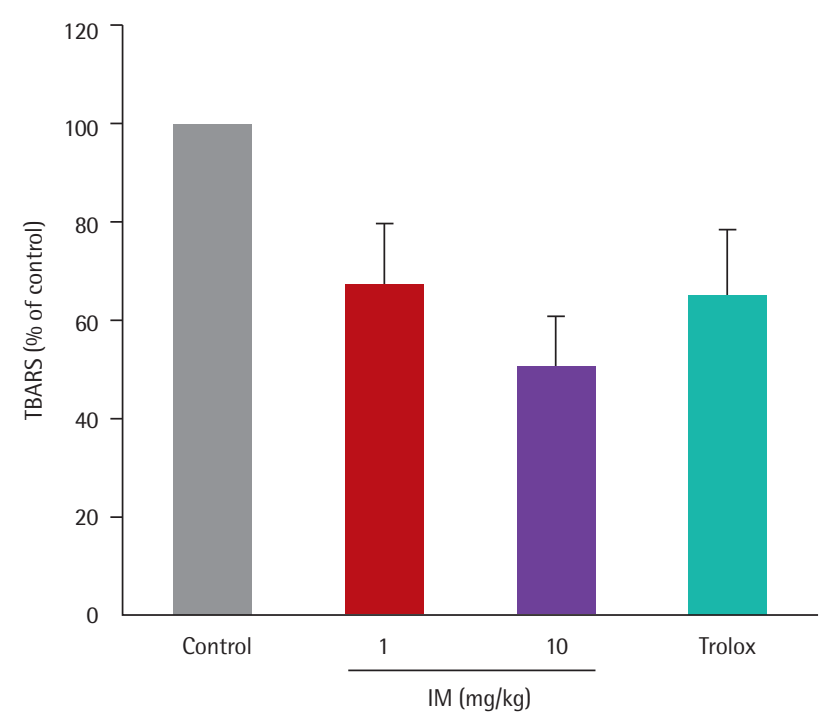

Figure 6. The $1 \mathrm{mg} / \mathrm{kg}$ and $10 \mathrm{mg} / \mathrm{kg}$ IM significantly inhibited the production of thiobarbituric acid reactive substances (TBARS). The antioxidant trolox administered at $25 \mathrm{mg} /$ $\mathrm{mL}$ also inhibited the production of TBARS.
Intracellular cAMP is raised by increased synthesis via the activation of adenylyl cyclase or decreased degradation via inhibition of PDEs, or both [11]. In this study, intracellular cAMP contents were significantly increased by IM alone or with SNAP compared with the control group, however, increased cAMP content by SNAP alone was not significant. Previous studies reported that the inhibitory effect of IM on inflammation was associated with an increase in intracellular cAMP contents by inhibition of PDEs [11,12]. Further studies to elucidate the detailed cellular signaling pathway involving cAMP and PDE contributing to the gastroprotection induced by IM is needed.

It is well known that NO produced by the activation of NO synthase in epithelial cells is involved in the regulation of gastric mucosal integrity $[11,20]$. Furthermore, it is important in the regulation of acid and alkaline secretins, mucus secretion, and gastric mucosal blood flow and gastric microcirculation. To investigate the role of NO in the gastroprotection of IM, L-NAME, the NO synthase inhibitor, was used to evaluate the protective effect of IM on ethanol/HCl-induced gastric ulcers. In the present study, IM- and L-arginine-induced gastroprotection was slightly reversed by L-NAME, suggesting that the gastroprotective effect of IM is mediated, in part, by NO. Previous reports suggest that IM and NO exhibit gastroprotective effects by increasing intracellular cAMP levels, supporting our present finding [11,12].

It is well known that endogenous prostaglandins act a protective factor to protect physiological functions of the stomach by activating $\mathrm{K}_{\text {ATP }}$ channels. Previous studies have also suggested the participation of $\mathrm{K}_{\text {ATP }}$ channels in the indomethacin- and ethanol-induced ulcer models, in which prostaglandins were shown as probable activators of these channels $[21,22]$. The present results showed that the gastroprotective effect of IM was $\mathrm{K}_{\mathrm{ATP}}$ channel-dependent, since it was reversed by pretreatment with glibenclamide, a potent antagonist of $\mathrm{K}_{\text {ATP }}$ channels. These observations suggest that prostaglandins synthesis is likely involved in the IM-induced gastric ulcer improvement.

It has been suggested that capsaicin-sensitive afferent neurons play a role in gastroprotection by interacting with or without TRPV1 and this effect involves endogenous prostaglandins $[23,24]$. To verify whether the gastroprotective effect of IM was related to TRPV1, capsaicin, 
a TRPV1 activator and capsazepine, a TRPVı blocker, were used in this experiment. In the present study, IM and capsaicin significantly reduced the gastric ulcer induced by ethanol/HCl, which was not significantly affected by the combined use of capsazepine, suggesting capsaicin-sensitive afferent neurons have no role in the gastroprotection by IM. In a recent study, activation of TRPV1 by capsaicin has been shown to increase gastric protection by increasing calcitonin gene-related peptide, and this effect was not affected by capsazepine.

Oxidative stress is known to be one of the main causes of many gastrointestinal diseases including stomach ulcers [25]. Oxidative stress is caused by the generation of free radicals and reactive metabolites, such as NO, superoxides, hydroxyl radicals and hydrogen peroxide. The occurrence of stomach ulcers is highly correlated with lipid peroxidation in mucosal cells due to increased superoxide anions. Previous studies have shown that ethanol/ $\mathrm{HCl}$ generates superoxide anions and hydroperoxy free radicals, which cause gastric ulcers $[4,6]$. It is also reasonable to assume that MPO may be an important source of ROS. In this study, ethanol/HCl significantly increased the lipid peroxidation and MPO activity compared with the sham treated group, and IM significantly reduced the production of TBARS in a concentration-dependent manner. Furthermore, a similar effect was demonstrated by trolox, suggesting that the antioxidant activity of IM might be mediated by inhibition of lipid peroxidation.

\section{KEY MESSAGE}

1. Alcohol is one of the most common pathogenic factors of gastric injury. Excessive alcohol consumption can weaken the protective function of the gastric mucosa. Alcohol is well-known to induce damage to the gastric mucosa including edema, erosion, ulcerative lesions, hemorrhage and infiltration of inflammatory cells in animal studies

2. Irsoglandine maleate significantly reduced the gastric ulcers induced by ethanol/hydrochloric acid $(\mathrm{HCl})$ which was caused by an increase in the protective mechanism of the gastric mucosa.

3. Furthermore, this protective effect could be re- lated to an enhanced gastric mucosal defensive mechanism, at least in part, involving the actions of nitric oxide and 3'5'-cyclic adenosine monophosphate (cAMP), endogenous prostaglandins, adenosine triphosphate-sensitive potassium $\left(\mathrm{K}_{\mathrm{ATP}}\right)$ channel opening, activation of and transient receptor potential cation channel subfamily V member 1, and antioxidant properties.

\section{Conflict of interest}

No potential conflict of interest relevant to this article was reported.

\section{REFERENCES}

1. Franke A, Teyssen S, Singer MV. Alcohol-related diseases of the esophagus and stomach. Dig Dis 2005;23:204-213.

2. Li CY, Xu HD, Zhao BT, Chang HI, Rhee HI. Gastroprotective effect of cyanidin 3-glucoside on ethanol-induced gastric lesions in rats. Alcohol 2008;42:683-687.

3. Jang SH, Lim JW, Kim H. Beta-carotene inhibits Helicobacter pylori-induced expression of inducible nitric oxide synthase and cyclooxygenase-2 in human gastric epithelial AGS cells. J Physiol Pharmacol 2009;60:131-137.

4. Das D, Banerjee RK. Effect of stress on the antioxidant enzymes and gastric ulceration. Mol Cell Biochem 1993;125:115125 .

5. Hamaishi K, Kojima R, Ito M. Anti-ulcer effect of tea catechin in rats. Biol Pharm Bull 2006;29:2206-2213.

6. Jaarin K, Renuvathani M, Nafeeza MI, Gapor MT. Comparative effect of palm vitamin $\mathrm{E}$ and ranitidine on the healing of ethanol-induced gastric lesions in rats. Int J Exp Pathol 1999;80:259-263.

7. Takahashi N, Joh T, Yokoyama Y, et al. Importance of gap junction in gastric mucosal restitution from acid-induced injury. J Lab Clin Med 2000;136:93-99.

8. Kamei K, Kubo Y, Kato N, Hatazawa R, Amagase K, Takeuchi K. Prophylactic effect of irsogladine maleate against indomethacin-induced small intestinal lesions in rats. Dig Dis Sci 2008;53:2657-2666.

9. Ueda F, Aratani S, Mimura K, Kimura K, Nomura A, Enomoto H. Effect of 2,4-diamino-6-(2,5-dichlorophenyl)-s-triazine maleate ( $\mathrm{MN}-1695)$ on gastric mucosal 
blood flow in dogs. Arzneimittelforschung 1984;34:485491.

10. Kyoi T, Oka M, Noda K, Ukai Y. Irsogladine prevents monochloramine-induced gastric mucosal lesions by improving the decrease in mucosal blood flow due to the disturbance of nitric oxide synthesis in rats. J Pharmacol Sci 2003;93:314-320.

11. Kyoi T, Oka M, Noda K, Ukai Y. Phosphodiesterase inhibition by a gastroprotective agent irsogladine: preferential blockade of cAMP hydrolysis. Life Sci 2004;75:1833-1842.

12. Yao J, Zhu Y, Sun W, et al. Irsogladine maleate potentiates the effects of nitric oxide on activation of cAMP signalling pathways and suppression of mesangial cell mitogenesis. Br J Pharmacol 2007;151:457-466.

13. Laine L, Takeuchi K, Tarnawski A. Gastric mucosal defense and cytoprotection: bench to bedside. Gastroenterology 2008;135:41-6o.

14. Shim KN, Kim JI, Kim N, et al. The efficacy and safety of irsogladine maleate in nonsteroidal anti-inflammatory drug or aspirin-induced peptic ulcer and gastritis. Korean J Intern Med 2019;34:1008-1021.

15. Ohkawa H, Ohishi N, Yagi K. Assay for lipid peroxides in animal tissues by thiobarbituric acid reaction. Anal Biochem 1979;95:351-358.

16. Kurebayashi Y, Ikeda T, Osada Y. Cytoprotective action of cetraxate against HCl.ethanol-induced gastric lesion in rats. Jpn J Pharmacol 1988;46:17-25.

17. Asai M, Kawashima D, Katagiri K, Takeuchi R, Tohnai G, Ohtsuka K. Protective effect of a molecular chaperone inducer, paeoniflorin, on the $\mathrm{HCl}$ - and ethanol-triggered gastric mucosal injury. Life Sci 2011;88:350-357.
18. Suo H, Zhao X, Qian Y, et al. Lactobacillus fermentum Suo attenuates $\mathrm{HCl} /$ Ethanol induced gastric injury in mice through its antioxidant effects. Nutrients 2016;8:155.

19. Ogawa K, Oyagi A, Tanaka J, Kobayashi S, Hara H. The protective effect and action mechanism of Vaccinium myrtillus L. on gastric ulcer in mice. Phytother Res 2011;25:11601165 .

20. Wallace JL. Nitric oxide, aspirin-triggered lipoxins and NO-aspirin in gastric protection. Inflamm Allergy Drug Targets 2006;5:133-137.

21. Santos Cerqueira G, dos Santos e Silva G, Rios Vasconcelos E, et al. Effects of hecogenin and its possible mechanism of action on experimental models of gastric ulcer in mice. Eur J Pharmacol 2012;683:260-269.

22. Morais TC, Pinto NB, Carvalho KM, et al. Protective effect of anacardic acids from cashew (Anacardium occidentale) on ethanol-induced gastric damage in mice. Chem Biol Interact 2010;183:264-269.

23. Fukushima K, Aoi Y, Kato S, Takeuchi K. Gastro-protective action of lafutidine mediated by capsaicin-sensitive afferent neurons without interaction with TRPV 1 and involvement of endogenous prostaglandins. World J Gastroenterol 2006;12:3031-3037.

24. Sepulveda B, Quispe C, Simirgiotis M, et al. Gastroprotective activity of synthetic coumarins: role of endogenous prostaglandins, nitric oxide, non-protein sulfhydryls and vanilloid receptors. Bioorg Med Chem Lett 2016;26:57325735.

25. Perez S, Talens-Visconti R, Rius-Perez S, Finamor I, Sastre J. Redox signaling in the gastrointestinal tract. Free Radic Biol Med 2017;104:75-103. 